\title{
USE OF INFORMATION TECHNOLOGY IN COMMUNITY RE-LOCATION OF A MENTALLY ILL PERSON- A CASE REPORT
}

Shilpa Waikar ${ }^{1}$,Anil Rane ${ }^{2}$,Yvonne Da Silva Pereira ${ }^{3}$.

1. Assistant Professor, Institute of Psychiatry and Human Behaviour, Bambolim Goa India.

2. Lecturer, Institute of Psychiatry and Human Behaviour, Bambolim Goa India.

3. Professor, Institute of Psychiatry and Human Behaviour, Bambolim Goa India.

\section{CORRESPONDING AUTHOR:}

Shilpa Waikar,

A-1/T-2, Essar Galaxy, Shankarwadi,

Taliegao Goa,

India-403002.

E-mail: shilpakerkar13@yahoo.co.in

\begin{abstract}
It is not unusual for mentally ill person to wander away from their homes under the influence of their illness. Often such wandering patients are admitted to mental health facilities under various provision of the mental health act (MHA) as prevalent in the country such as the use of Reception Order (RO) under the Indian mental health act. Many a times because of long standing nature of illness, intellectual sub-normality, long duration of untreated psychosis and associated cognitive impairment these patients are unable to give adequate details of their residence especially those out of state and tend to languish for long periods in mental health care facilities. We present one such out of state patient with inadequate residential details who was relocated back to her community with the help of modern internet based information technology.
\end{abstract}

KEY WORDS- Information technology, Relocation, Mentally ill

INTRODUCTION: Computer and internet technology have pervaded human lives and their use in academics, research, and delivery of health care services are familiar to us. There are much more uses of the internet that could be used for patient care. We have used this internet based information technology, websites and wikimapia, for tracing the house of one of our patients with inadequate residential address.

It is not uncommon for mentally ill person to wander away from their homes under the influence of hallucinations and delusions. Many of these patients may have subnormal intelligence and do not have a fixed destination to travel. Some times because of longstanding nature of the illness and inadequate treatment, they may have decreased cognitive abilities ${ }^{1}$. This in turn leads to giving inadequate details about self. Often such wandering patients are admitted to mental health facilities under provisions of the mental health act (MHA). Under the Indian MHA 2 those found not to be under proper care, are picked up by the police and admitted to mental hospitals under reception order of a magistrate, such a provision has been shown to be useful to bring such wandering patients under mental health care ${ }^{3}$.

Using available information we usually succeed in uniting patients back with their families. However, despite our best efforts sometime re-locating patients is a great challenge especially when patient is unable to share relevant information. The objective of writing this case report is to 


\section{CASE REPORT}

describe, how we used modern internet based information technology- Wikimapia ${ }^{4}$ and other websites to relocate our patient, who could not give adequate postal address and did not have any other means of communication.

CASE REPORT: A female patient approximately 25 years of age, by name A (only first name known) was admitted at our centre, a teaching hospital, in 2007 by RO. At admission she had disheveled appearance and would smile for no apparent reason. Her attention was aroused but concentration was ill sustained and would answer in Hindi and was irrelevant most of the time. Her baseline biochemical investigations were within normal limits. Based on available history, observation in the ward and mental status examination, a provisional diagnosis of Psychotic Disorder NOS (DSM IV) ${ }^{5}$ was made and treatment initiated.

We were able to collect the history, in bits and part along with nursing staff and psychiatric social worker (PSW) over the course of time. Over five to six weeks, some information could be collected from her. She gave the first names of her parents, her father worked in a government department, she came from Garwa, Bihar and that her village had a government hospital, a girl's school with a big parade ground and one of her neighbor (only first name known) had a telephone, but she did not know the phone number. She could not provide much information on her other details like marriage and children or how she reached so far away from home. She did not give any details about her past psychiatric illness, but mentioned that she was frequently being taken to Oza to get evil spirits out of her body. Despite all efforts we could not obtain adequate information to communicate with her family.

Attempts were made to locate the patient's village in Bihar to get in touch with her guardians. Bharat Sanchar Nigam Limited helpline, information from postal departments, post office website, various online maps and other relevant website were searched using different spellings of her village (gadwa, ghadwa, ghadwha, gedwa) without much success.

After about two months of inpatient stay, she could remember that her village had a railway station and she had gone to "Daulataganj", a nearby town with her mother. We managed to locate Daltonganj instead of Daulatganj online and also found Garhwa (Gadwa) in the state of Jharkhand and not in Bihar.

Using the online geospatial mapping facility of wikimapia we managed to identify all the details she had provided to us so far, such as the patient's location of her home in Garhwa, the railway station, parade ground, school and hospital. Phone number of the respective police department was searched from Government of Jharkhand website and the police department was contacted, the patient's details matched with the missing complain filed by patient's father. Patient's father reported along with the police for her discharge. The patient identified the father and was discharged.

DISCUSSION: The legal system does help wandering mentally ill by admitting to a treatment centre but the residual psychosis and cognitive impairment come in the way of family reintegration. It took two months for our patient (after starting the treatment) to give some landmark of her hometown. Her hometown Garhwa was initially part of Bihar and later became part of Jharkhand, the $28^{\text {th }}$ state of the Indian Union, since November 15, 20006. Probably our patient was referring about the political boundaries seven years before admission at our centre. It was the Internet based information technology that searched her hometown and the phone numbers and we were able to 


\section{CASE REPORT}

contact the family members.

According to Harry Minas and Hervita Diatri one of the reasons for physical confinement of mentally ill by their relatives is their concern about the person wandering off or running away 7 . Wandering off not only causes emotional turmoil to the families but also makes the person vulnerable to physical, emotional and psychological abuse and other kinds of exploitation. Such patients, in absence of adequate information, languish for longer duration in mental hospitals and strain the already scarce mental health resources ${ }^{3}$.

There is a great need to develop a Systematic Re-integration policy and common platform to deal with problems of relocation and reintegration of such wandering mentally ill persons. Use of AADHAAR $^{8}$, a twelve-digit individual unique identification number system with biometric parameters and address may be a viable option. This will require the collaborative participation of policy makers, judiciary, police department, mental health professionals and NGOs in the field.

CONCLUSION: we strongly recommend policy makers to make adequate number of psychiatric facilities available so that patients are diagnosed and treated early and adequately thereby reducing wandering off of patients. We also emphasize on the need to make an integrated platform services to relocate and rehabilitate such wandering mentally ill patient and hope that the new mental health act makes provision for the same.

ACKNOWLEDGEMENT: The authors wish to acknowledge Ms Mahalaxmi Bhobe for her contribution in relocating the patient.

\section{REFERENCE:}

1. Amminger G. P, Edwards J, Brewer W J, Harrigan S, McGorry P D. Duration of untreated psychosis and cognitive deterioration in first-episode schizophrenia. Schizophrenia research. 2002; 54(3): 223-230.

2. The mental Health Act.1987. Gazette of India (1987) extraordinary Part II, Section I: Government of India, ministry of law and Justice-1987 May 22. Act No. 14 of 198

3. Rane A, Nadkarni A, Waikar S, Borker H A. Judicial involuntary admission under the Mental health act in Goa, India: profile, outcome and implications. Int Psychiatry. 2012 Nov; 9(4): 98-101.

4. Website of wikimapia [Internet]. 2012 [cited 2013 May 17]. Available from: http://wikimapia.org/

5. Diagnostic and statistical manual of mental disorders: DSM-IV. Washington, DC: American Psychiatric Association. 2000.

6. Official website of government of Jharkhand [Internet]. [cited 2013 May 17] Available from: http://www.jharkhand.gov.in/AboutState_fr.html

7. Minas H, Hervita D. Pasung: Physical restraint and confinement of the mentally ill in the community. Int J Ment Health Syst. 2008 June 16; 2: 8. doi: 10.1186/1752-4458-2-8

8. Official website of Unique Identification Authority of India, planning commission, government of India [Internet]. [cited 2013 May17]. Available from: http://uidai.gov.in/what-is-aadhaar-number.html 